\title{
Marketing Mix-Based Facebook Posts and Potential Consumers: An Abstract
}

\author{
Benjamin K. Wright
}

\begin{abstract}
The overall purpose of this study was to test the relationship between satisfaction of marketing mix-related social media communications (i.e., Facebook posts), brand equity, and purchase intention within a fitness setting. Although fitness and the promotion of healthy lifestyles have become commonplace in our society, health and fitness clubs continue to face membership issues. In fact, only $16 \%$ of Americans belong to health/fitness clubs (Steiman, 2014). Furthermore, research has indicated that fitness club members typically end their membership due to what could be deemed brand-related issues (Tharrett \& Peterson, 2012; Williams, Pedersen, \& Walsh, 2012). Subsequently, there is a need to improve the fitness industry's business practices regarding the rising number of health club brands and lack of consumption of the services provided by the industry.

To test the proposed model, data were collected from a sample of 393 prospective fitness club members. After being exposed to sample Facebook posts from a simulated fitness club brand relating to marketing mix dimensions (e.g., product, price, place, promotion, people, physical evidence, and process), participants responded to items aimed to measure social media communication satisfaction, brand equity, and purchase intention. Structural equation modeling (SEM) indicated that the relationship between social media communication satisfaction and brand equity and brand equity and purchase intention was both positive and significant. Consequently, the results of this study suggest that satisfaction of certain Facebook posts may lead to the development of brand equity and purchase intention for fitness club prospects.
\end{abstract}

References Available Upon Request

\author{
B.K. Wright $(\bowtie)$ \\ Ball State University, Muncie, IN, USA \\ e-mail: benjaminkwright@gmail.com
}

